\title{
Thermal Decomposition Properties of Industrial Oily Sludge under Different Atmospheres
}

\author{
Shaobiao Zhang ${ }^{1,2}$, Huichun Jiang ${ }^{3}$, Dayong $\mathrm{Xu}^{3 *}$, Lili Yang ${ }^{2}$, Shufeng $\mathrm{Xi}^{3}$ \\ ${ }^{1}$ Harbin Institute of Technology, Harbin, 150090, China \\ ${ }^{2}$ Southern University of Science and Technology, Shenzhen, 518055, China \\ ${ }^{3}$ Shenzhen Urban Public Safety and Technology Institute, Shenzhen, 518046, China
}

Received: 6 August 2021

Accepted: 21 October 2021

\begin{abstract}
The environmentally friendly degradation of and energy recovery from oily sludge is a common concern in both research and industry. In this study, industrial oily sludge was collected after wastewater treatment by oil storage corporations. First, the physical and chemical properties of the samples were observed. Then, samples were analyzed using thermogravimetry-gas chromatography-mass spectrometry under air atmosphere and under nitrogen atmosphere. The characteristics of the residue after thermal decomposition were determined through Fourier-transform infrared spectroscopy, scanning electron microscopy, and energy dispersive spectrometry. The results revealed that the thermal degradation of oily sludge is divided into three steps under nitrogen atmosphere but four steps under air atmosphere. Moreover, thermal decomposition was mainly exothermic under nitrogen atmosphere but endothermic under air atmosphere. The mass loss of oily sludge was greater under air atmosphere. The final residue was $26.6 \%$ under an air atmosphere, which was lower than the $35.8 \%$ observed under nitrogen atmosphere. The gaseous products of oily sludge included gaseous fuels under nitrogen atmosphere but were only combustion products under air atmosphere. In both atmospheres, the solid products remaining in the residue were the metallic elements $\mathrm{Fe}, \mathrm{Al}, \mathrm{Mg}, \mathrm{Na}$, and $\mathrm{Ca}$, which can be reused in desulfurization applications.
\end{abstract}

Keywords: oily sludge, energy recovery, waste treatment, thermal decomposition process, gaseous products

\section{Introduction}

Main text paragraph. Oil plays an indispensable role in global energy infrastructure [1]. Most cities establish large-scale oil storage tank farms to meet the rapidly growing demand for oil [2]. During the storage and transportation of oil, hazardous waste is inevitably produced [3]. Oily sludge is a common solid waste product of oil storage tank farms that is produced both by deposition in tanks and as a byproduct of wastewater treatment [4]. According to a survey, an oil storage corporation might produce dozens of tons of oily sludge every year. Because oily sludge can contain polycyclic aromatics, heavy metals, and even radioactive material, it is a potential threat to human health and environmental safety [5].

*e-mail: xudy@szsti.org 
Although oily sludge is a dangerous form of pollution, it is also a potentially recyclable energy source $[6,7]$. Usually, oily sludge has high amounts of hydrocarbons and heavy metals, which can be recycled and reused $[8,9]$. Therefore, worldwide research into degradation treatments of and resource recovery from oily sludge has been extensive [10]. Research is ongoing into the critical problem of developing a safe, green, efficient, and economic method of degrading oily sludge.

Present degradation and recovery methods for oily sludge include centrifugal separation [11], solvent extraction [12], stabilization and solidification [13], biodegradation [14], and thermal decomposition [15]. These methods describe feasible treatments for oily sludge, but research into their mechanisms is insufficient. Among these methods, thermal decomposition primarily realizes the degradation and recovery of oily sludge by using combustion and pyrolysis [16, 17]. Chen et al. [18] investigated N/S/ $\mathrm{Cl}$ pollutants during the pyrolysis and combustion of oily sludge by using thermogravimetry (TG)-mass spectrometry and pyrolysis-gas chromatography-mass spectrometry. Petrovsky et al. [19] briefly introduced the pyrolysis method of treating oily sludge and described the mechanism of thermal destruction of hydrocarbons in oily sludge. Tang et al. [20] used a newly developed industrial-scale reactor to analyze the pyrolysis of oily sludge and to characterize the composition of products from pyrolysis at temperatures between 450 and $600^{\circ} \mathrm{C}$. Liu et al. [21] evaluated the thermal characteristics and kinetics of oily sludge, litchi peels, and their blends by using TG experiments under air atmosphere, revealing that blending inhibits devolatilization and promotes char oxidation. In contrast to combustion, when oily sludge is pyrolyzed under nitrogen atmosphere, hydrocarbons can be released and recycled. Some researchers have attempted to maximize resource recovery through the copyrolysis of oily sludge with additives such as rice husk, walnut shell, sawdust, apricot shell, and polyolefin [22-24]. Therefore, in the pursuit of maximizing resource recovery from oily sludge treatment, pyrolysis and copyrolysis offer an opportunity for technological advancement.

The aim of this study was to evaluate the effects of atmosphere on the degradation of sludge and recovery of hydrocarbons during the thermal decomposition of oil sludge. First, a TG analysis of oily sludge was performed under nitrogen atmosphere and air atmosphere. Then, a TG-Fourier-transform infrared (TG-FTIR) spectrometer was used to track the gases produced during thermal decomposition in real time. Finally, a Fourier-transform-infrared-(FTIR) spectrometer, a scanning electron microscope (SEM), and an energy dispersive spectrometer (EDS) were used to characterize the composition and microstructure of the solid residue after thermal decomposition. In summary, this study analyzed the thermal decomposition of oily sludge over a large temperature range with a focus on degradation and resource recovery capacities under nitrogen and air atmospheres.

\section{Material and Methods}

\section{Samples}

Oily sludge was obtained from a large oil storage corporation in Dapeng County, Shenzhen City, Guangdong Province, China. The sludge was produced during wastewater treatment. The oily sludge was a dark viscous slurry without particulates. The initial composition of the sample was determined by proximate and ultimate analysis. Table 1 lists exactly the contents of moisture $(\mathrm{M})$, volatile matter $(\mathrm{V})$, fixed carbon $(\mathrm{FC})$, ash (A), and organic elements (C, H, O, N, and S).

Because of its high moisture content, the sample was dehydrated at $80.0^{\circ} \mathrm{C}$ for $2.0 \mathrm{~h}$ in a vacuum drying oven (DZF-6050, Shanghai Jing Hong Laboratory Instrument Co, Ltd., Shanghai, China).

\section{Experiments}

\section{Proximate and Ultimate Analysis}

The moisture $(\mathrm{M})$, volatile matter $(\mathrm{V})$, fixed carbon (FC), and ash (A) content were determined using a muffle furnace according to the Chinese standard for the proximate analysis of coal (GB/T 212-2008). The content of organic elements $(\mathrm{C}, \mathrm{H}, \mathrm{O}, \mathrm{N}$, and $\mathrm{S})$ was characterized using an elemental analyzer (Vario EL Cube, Elementar Analysensysteme $\mathrm{GmbH}$, Langenselbold, Germany).

$T G$

The thermal decomposition processes of the oily sludge were performed using TG (TGA/DSC 3+, Mettler Toledo, Zurich, Switzerland). A 10.0 $\pm 0.2-\mathrm{mg}$ sample was spread uniformly in a $100 \mu \mathrm{L}$ alumina crucible. The mass of the sample was measured as it was heated from 25.0 to $1000.0^{\circ} \mathrm{C}$ at $5.0^{\circ} \mathrm{C} \cdot \mathrm{min}^{-1}$.

Table 1. Results of proximate and ultimate analysis of oily sludge.

\begin{tabular}{|c|c|c|c|c|c|c|c|c|c|}
\hline \multirow{2}{*}{ Material } & \multicolumn{4}{|c|}{ Proximate analysis $/ \mathrm{wt} \%$} & \multicolumn{5}{c|}{ Ultimate analysis $/ \mathrm{wt} \%$} \\
\cline { 2 - 11 } & $\mathrm{M}$ & $\mathrm{V}$ & $\mathrm{A}$ & $\mathrm{FC}$ & $\mathrm{C}$ & $\mathrm{H}$ & $\mathrm{O}$ & $\mathrm{N}$ & $\mathrm{S}$ \\
\hline Oily sludge & 34.90 & 13.92 & 8.25 & 77.83 & 2.41 & 6.36 & 44.46 & 0.30 & 0.16 \\
\hline
\end{tabular}


In both the air and nitrogen atmosphere experiments, gas was injected at a flow rate of $50.0 \mathrm{~mL} \cdot \mathrm{min}^{-1}$.

\section{TG-FTIR}

The TG-FTIR system comprises a TG (TGA 2, Mettler Toledo, Zurich, Switzerland) coupled with an FTIR (Tensor II, Bruker Corporation, MA, USA) through a pipe and flow cell. TG-FTIR experiments were performed at a heating rate of $5.0^{\circ} \mathrm{C} \cdot \mathrm{min}^{-1}$ under nitrogen and air atmospheres. The real-time infrared spectra data were collected from 4000 to $400 \mathrm{~cm}^{-1}$.

\section{FTIR, SEM, and EDS}

The FTIR (Vertex 80, Bruker Corporation, MA, USA) was used to analyze the functional groups of the thermal decomposition products of the oily sludge. The infrared spectra data were collected from 4000 to $400 \mathrm{~cm}^{-1}$.

The SEM (Zeiss Sigma 300, Carl Zeiss, Jena, Germany) and EDS (XFlash 6, Bruker Corporation, Massachusetts, USA) were used to analyze the microstructure and composition of the char. The sample was coated with a thin layer of gold by using a sputter coater.

\section{Results and Discussion}

\section{Thermal Decomposition Process Analysis}

The TG, derivative TG (DTG), and normalized heat flow curves of oily sludge at a heating rate of $5.0^{\circ} \mathrm{C} \cdot \mathrm{min}^{-1}$ under air and nitrogen atmospheres are compared in Figs 1-3, respectively. The critical thermodynamic parameters of onset decomposition temperature $\left(T_{0}\right)$, peak decomposition temperature $\left(T_{\mathrm{p}}\right)$, inflection point temperature $\left(T_{i \mathrm{p}}\right)$, end decomposition temperature $\left(T_{\mathrm{ed}}\right)$, and residual mass $(r)$ at different reaction stages are listed in Table 2. In both air and nitrogen atmospheres, oily sludge lost mass at the beginning of TG experiments. As the temperature increased, the thermal decomposition of oily sludge had distinct characteristics under nitrogen and air atmospheres.

When the oily sludge was heated under air atmosphere, the thermal decomposition process could be divided into four stages. The first stage occurred between 51.0 and $205.0^{\circ} \mathrm{C}$, and the mass loss as approximately $14.8 \%$. The second stage occurred between 205.0 and $454.0^{\circ} \mathrm{C}$, and the mass loss was approximately $37.0 \%$. The third stage occurred between 454.0 and $586.0^{\circ} \mathrm{C}$, and the mass loss was approximately $21.6 \%$. After reaching $586.0^{\circ} \mathrm{C}$, the mass of sample remained largely unchanged, leaving a residual of $26.6 \%$ of the original mass. When the oily sludge was heated under nitrogen atmosphere, the initial thermal decomposition process was similar to that under air atmosphere. By contrast, the mass of the sample heated

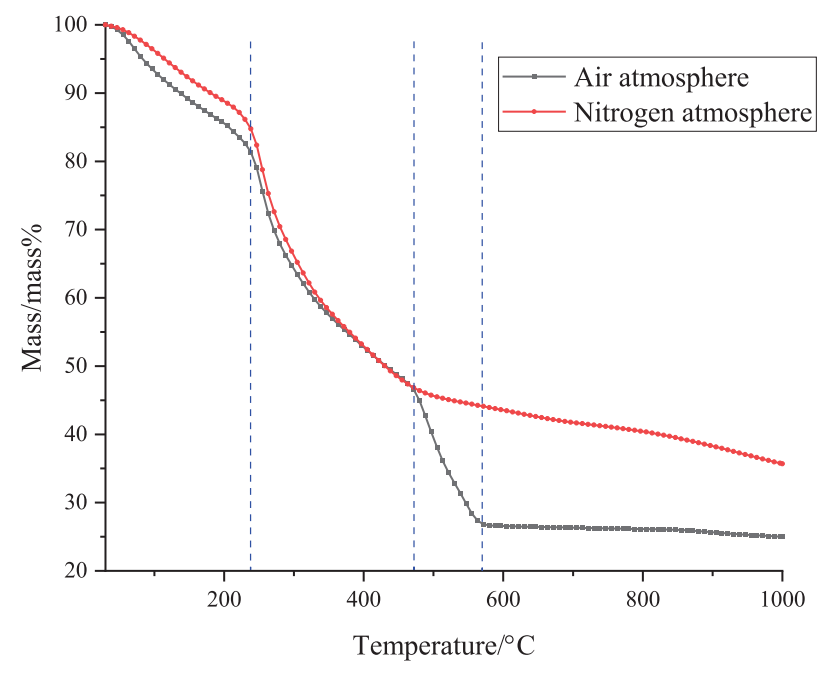

Fig. 1. TG curves of oily sludge under air and nitrogen atmospheres.

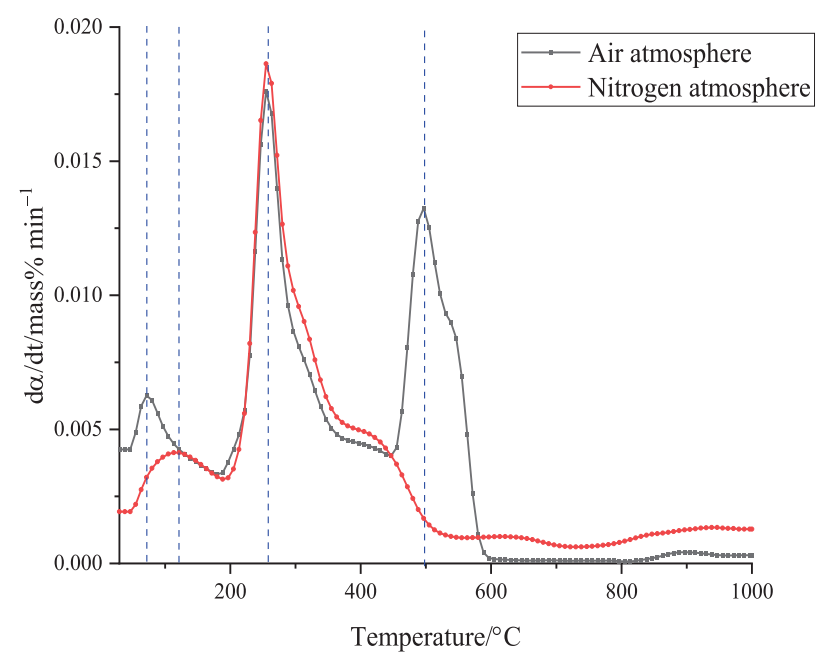

Fig. 2. DTG curves of oily sludge under air and nitrogen atmospheres.

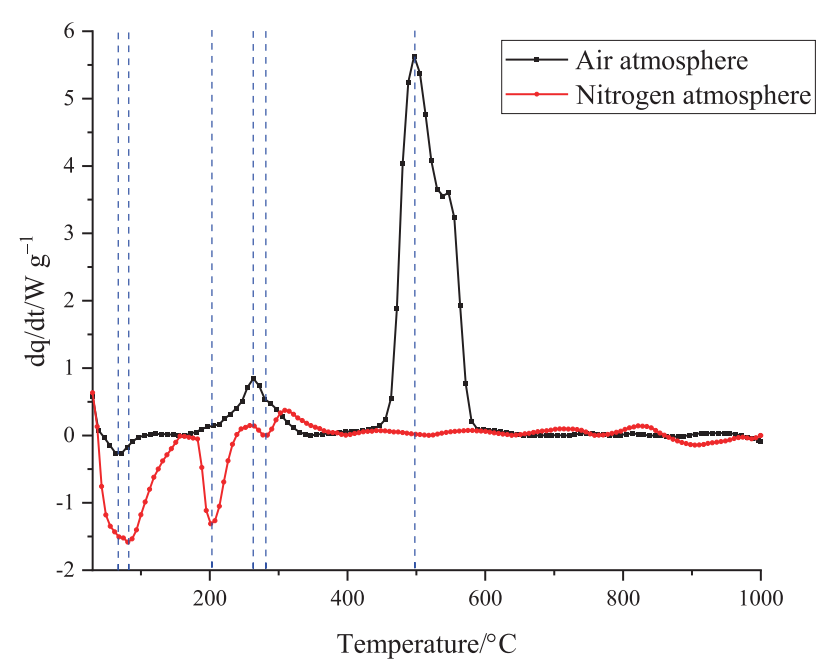

Fig. 3. Normalized heat flow of the thermal decomposition reaction of oily sludge under air and nitrogen atmospheres. 
Table 2. Relevant thermodynamic parameters of oily sludge under air and nitrogen atmospheres.

\begin{tabular}{|c|c|c|c|c|c|c|}
\hline Atmosphere & Stage & $T_{0} /{ }^{\circ} \mathrm{C}$ & $T_{\mathrm{p}} /{ }^{\circ} \mathrm{C}$ & $T_{\text {ip }} /{ }^{\circ} \mathrm{C}$ & $T_{\text {ed }} /{ }^{\circ} \mathrm{C}$ & $r /$ mass $\%$ \\
\hline \multirow{4}{*}{ Air } & Stage 1 & 51.0 & 73.0 & 205.0 & - & 85.2 \\
\cline { 2 - 7 } & Stage 2 & - & 258.0 & 454.0 & - & 48.2 \\
\cline { 2 - 7 } & Stage 3 & - & 496.0 & - & 586.0 & 26.6 \\
\hline \multirow{3}{*}{ Nitrogen } & Stage 1 & 50.0 & 121.0 & 204.0 & - & 88.5 \\
\cline { 2 - 7 } & Stage 2 & - & 255.0 & - & - & 35.8 \\
\hline
\end{tabular}

under nitrogen atmosphere continued to decrease as the temperature increased to $1000.0^{\circ} \mathrm{C}$. However, the mass loss rate of the sample under nitrogen atmosphere rapidly decreased after $450.0^{\circ} \mathrm{C}$. The final residue of sample under nitrogen atmosphere was $35.8 \%$ of the original mass. As can be seen in Fig. 3, regarding the heat released in the two conditions, the samples mainly produced endothermic peaks under air atmosphere but produced exothermic peaks under nitrogen atmosphere. Two exothermic peaks were detected when the sample was heated under nitrogen atmosphere. When the sample was heated under air atmosphere, one exothermic and two endothermic peaks were detected. The maximum endothermic peak occurred between 454.0 and $586.0^{\circ} \mathrm{C}$.

\section{Gas Products Analysis}

The three-dimensional FTIR spectra of gas products of oily sludge under nitrogen and air are presented in Figs 4 and 5. The FTIR spectral intensity along the time axis corresponds to the thermal decomposition process as found by TG analysis [25]. According to the thermal decomposition properties of samples, the FTIR spectra at peak temperatures under two conditions are extracted. Fig. 6 shows the FTIR spectra of gas products at 74.0, 253.0, 261.0, 497.0, and $810.0^{\circ} \mathrm{C}$ under air atmosphere. $\mathrm{CO}_{2}$ and $\mathrm{H}_{2} \mathrm{O}$ were the main gas products when the oily sludge was heated under air atmosphere. This result is consistent with hydrocarbon combustion. Fig. 7 shows the FTIR spectra of gas products at 119.0, 254.0, 259.0, and $947.0^{\circ} \mathrm{C}$ under nitrogen atmosphere. In comparison to Fig. 6, more functional groups are observed in Fig. 7. In particular, at $259.0^{\circ} \mathrm{C}, \mathrm{HCOO}^{-}$at $1180 \mathrm{~cm}^{-1},-\mathrm{CH}_{3}$ at $1370 \mathrm{~cm}^{-1},-\mathrm{CH}_{2}-$ at $2982 \mathrm{~cm}^{-1}$, and $-\mathrm{OH}$ at $3590 \mathrm{~cm}^{-1}$ are observed. These observations suggest that oily sludge can produce fuel gases when pyrolyzed under nitrogen atmosphere. Moreover, pyrolysis at the peak thermal decomposition temperature of $259.0^{\circ} \mathrm{C}$ achieves the maximum yield.

\section{Solid Products Analysis}

To analyze the components of solid products after thermal decomposition under different atmospheres,

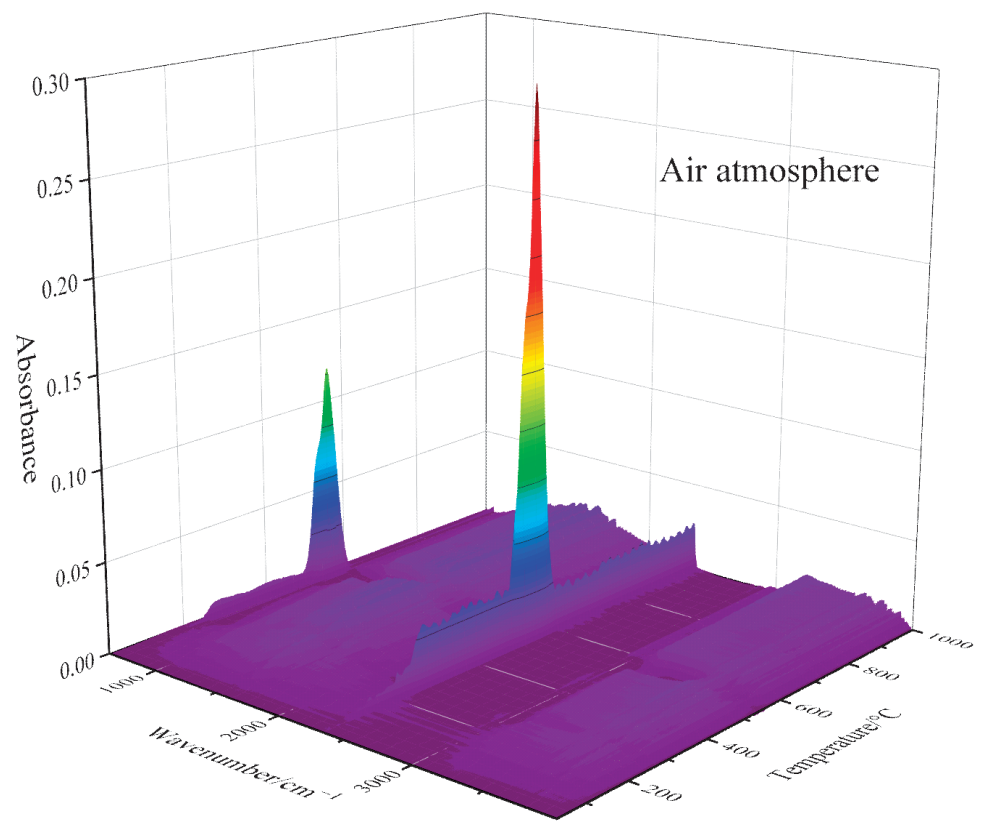

Fig. 4. Three-dimensional infrared spectra of oily sludge under air atmosphere. 


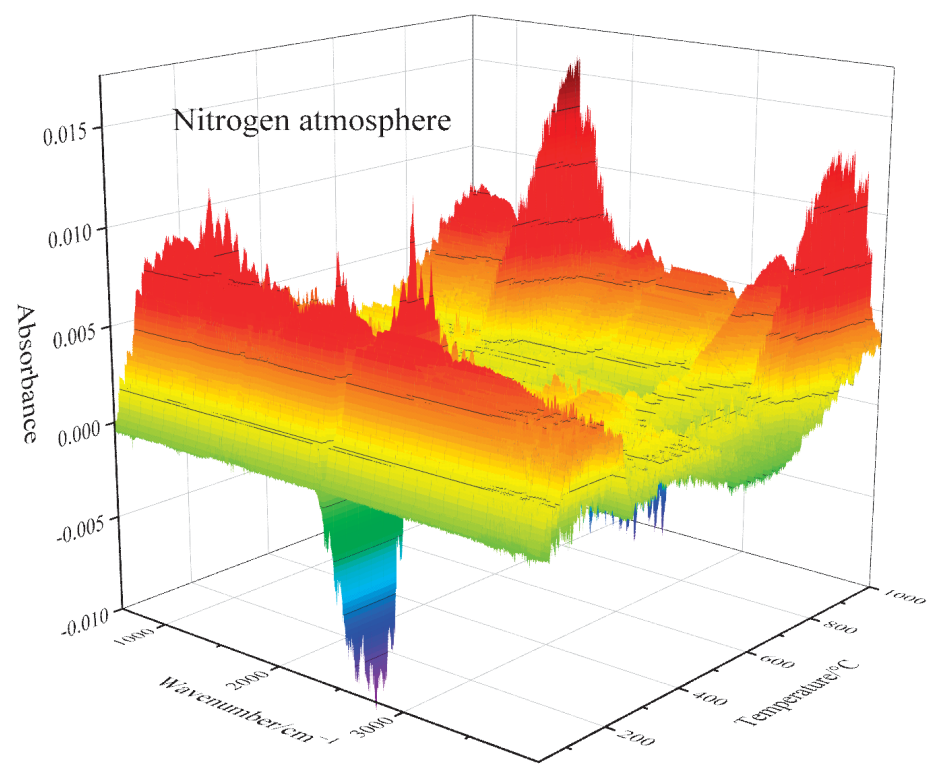

Fig. 5. Three-dimensional infrared spectra of oily sludge under nitrogen atmosphere.

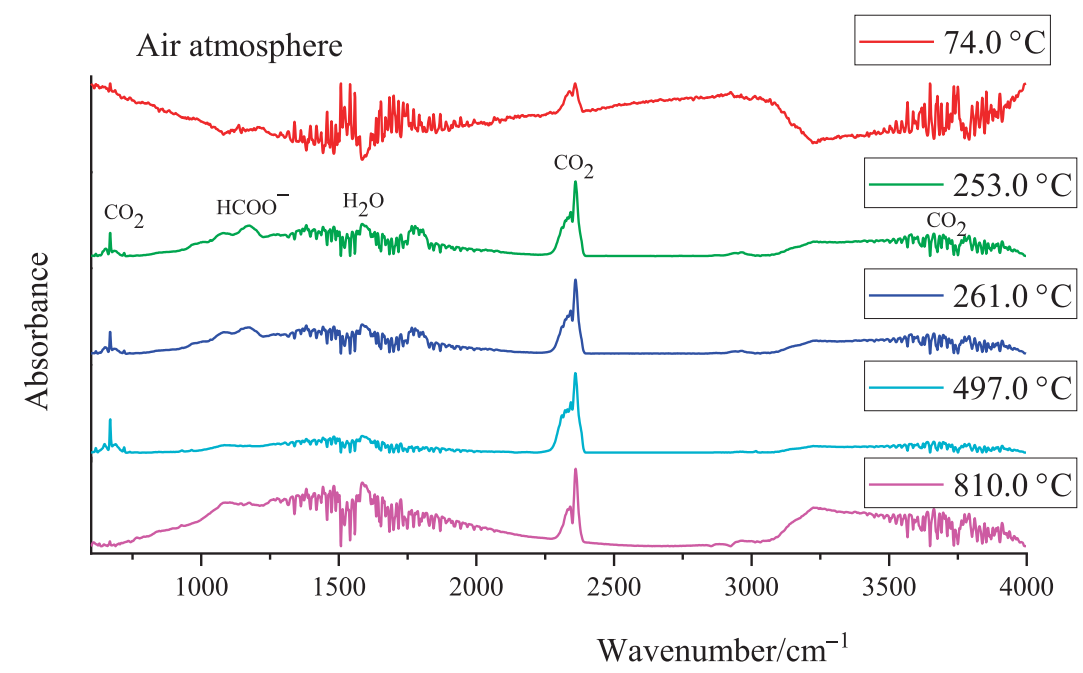

Fig. 6. Infrared spectra of oily sludge at peak temperature under air atmosphere.

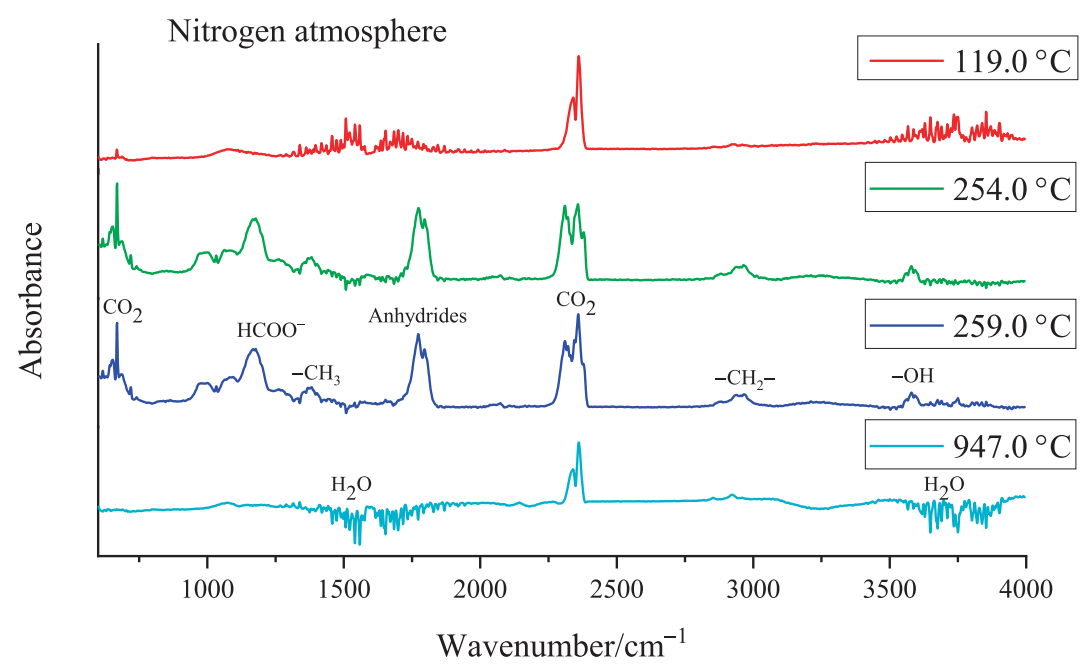

Fig. 7. Infrared spectra of oily sludge at peak temperature under nitrogen atmosphere. 


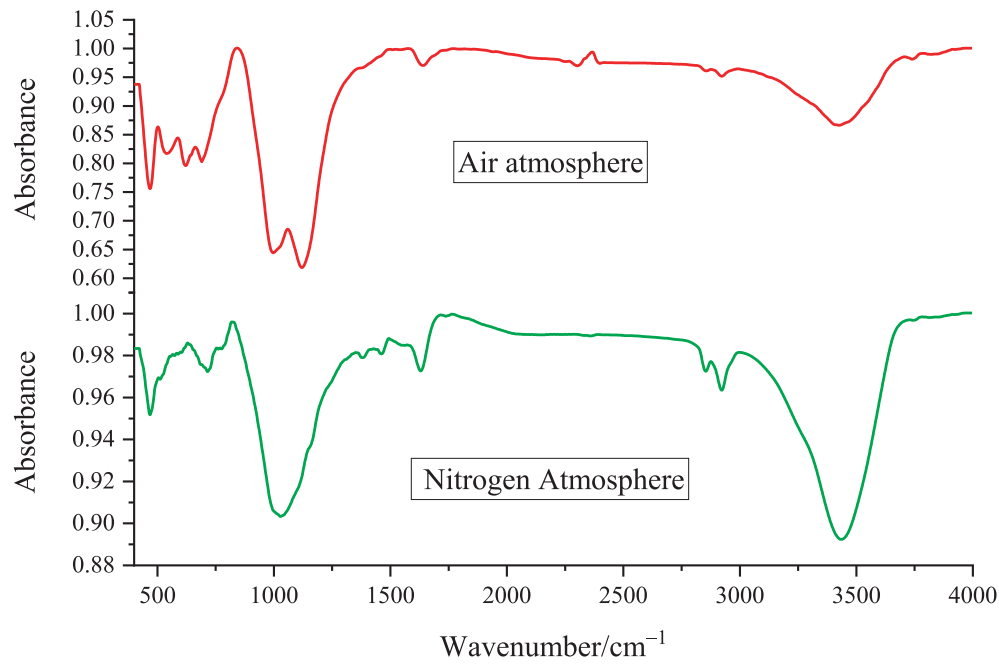

Fig. 8. Infrared spectra of oily sludge residue chars under air and nitrogen atmospheres.

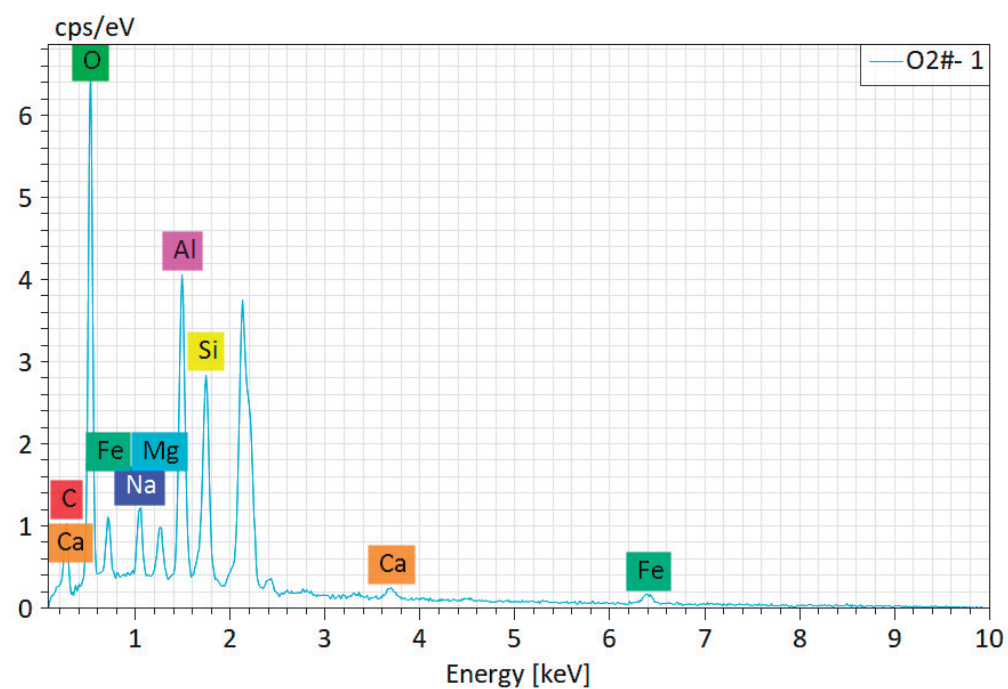

Fig. 9. Energy spectra of oily sludge residue chars under air atmosphere.

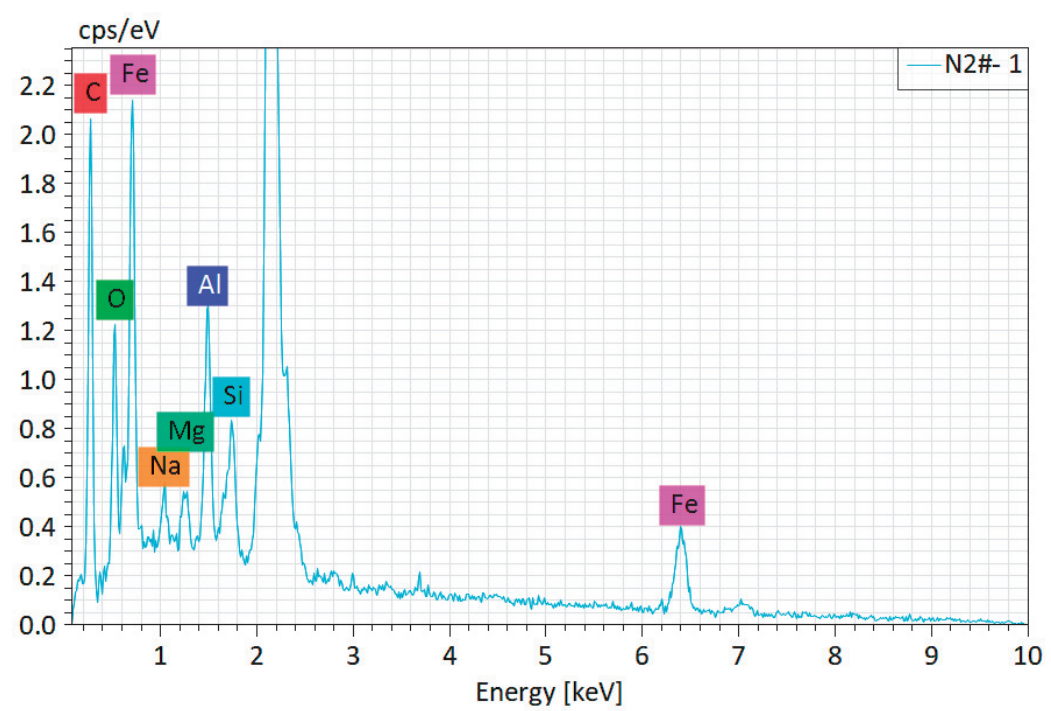

Fig. 10. Energy spectra of oily sludge residue chars under nitrogen atmosphere. 
Table 3. Normalized mass fractions of oily sludge residue chars under air and nitrogen atmospheres.

\begin{tabular}{|c|c|c|c|c|c|c|c|c|c|}
\hline \multicolumn{2}{|c|}{ Spectrum } & Carbon / & Oxygen / & Sodium / & Magnesium & Aluminium & Silicon / & Calcium / & Iron $/ \mathrm{wt} \%$ \\
\hline \multirow{5}{*}{ Air } & $\# 1$ & 10.33 & 37.82 & 4.18 & 2.51 & 15.27 & 16.04 & 2.40 & 11.44 \\
\hline & $\# 2$ & 5.43 & 34.14 & 1.67 & 2.67 & 6.80 & 11.02 & 20.00 & 18.27 \\
\hline & Mean & 7.88 & 35.98 & 2.93 & 2.59 & 11.03 & 13.53 & 11.20 & 14.85 \\
\hline & Sigma & 3.46 & 2.60 & 1.78 & 0.11 & 5.99 & 3.55 & 12.45 & 4.83 \\
\hline & Sigma Mean & 2.45 & 1.84 & 1.26 & 0.08 & 4.24 & 2.51 & 8.80 & 3.42 \\
\hline \multirow{5}{*}{ Nitrogen } & $\# 1$ & 22.74 & 6.78 & 1.98 & 1.82 & 6.89 & 5.56 & 0.00 & 54.24 \\
\hline & $\# 2$ & 30.72 & 12.18 & 2.25 & 1.80 & 7.69 & 8.26 & 17.24 & 19.87 \\
\hline & Mean & 26.73 & 9.48 & 2.12 & 1.81 & 7.29 & 6.91 & 17.24 & 37.05 \\
\hline & Sigma & 5.64 & 3.82 & 0.20 & 0.02 & 0.57 & 1.91 & 0.00 & 24.31 \\
\hline & Sigma Mean & 3.99 & 2.70 & 0.14 & 0.01 & 0.40 & 1.35 & 0.00 & 17.19 \\
\hline
\end{tabular}
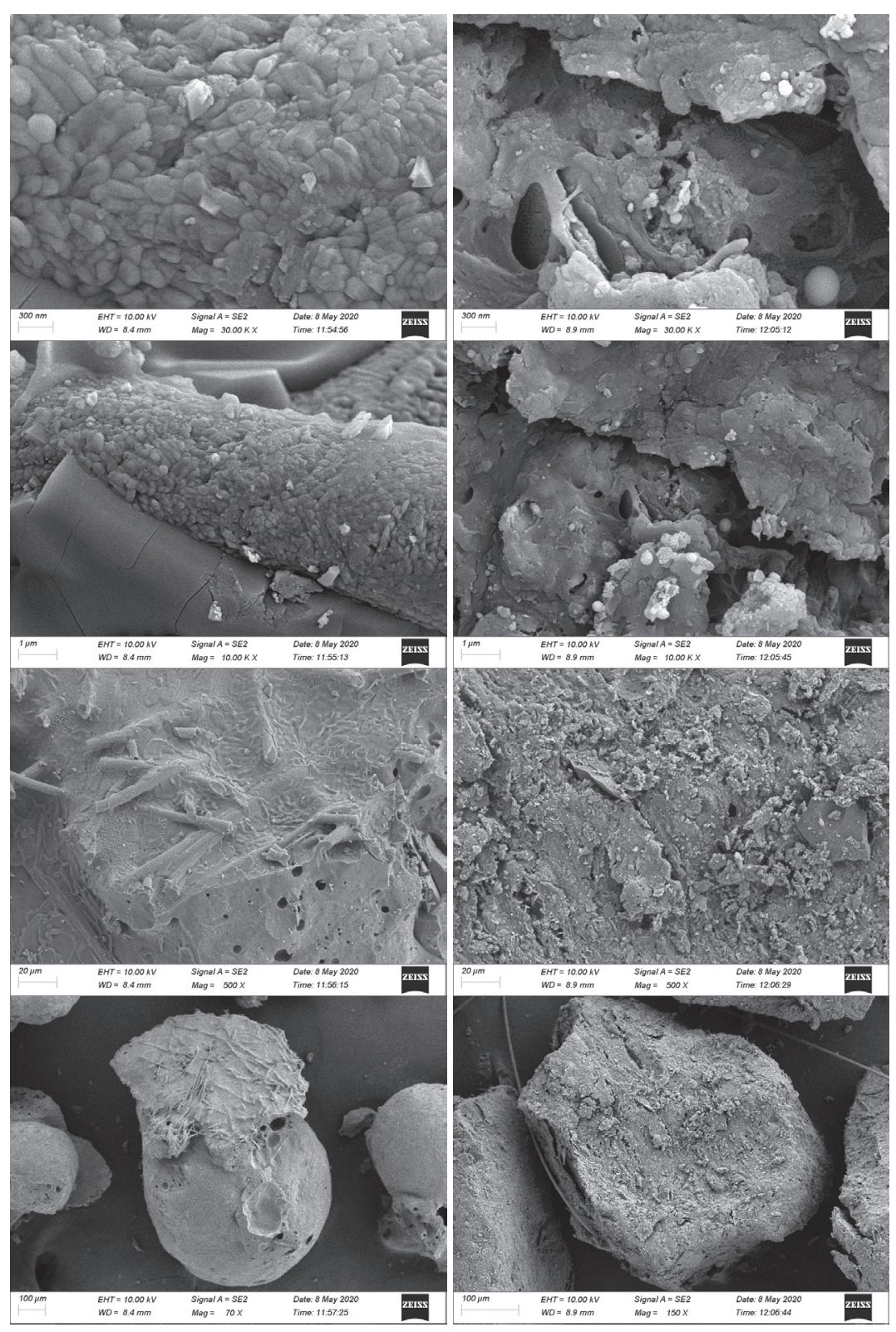

Fig. 11. SEM photographs of oily sludge residual chars under air (left side) and nitrogen (right side) atmospheres. 
the microcharacterization technologies of FTIR, SEM, and EDS were separately applied in this study. First, Fig. 8 shows that the FTIR spectra of solid products of oily sludge under two atmospheres are similar. It means that the influence of air and nitrogen on the solid products of oily sludge is negligible. Then, EDS was used to quantitatively analyze the microcomponents of solid products. The Energy spectra of solid products under air and nitrogen atmospheres were drawn in Fig. 9 and Fig. 10, respectively. The Corresponding quantitative data were listed in Table 3. The EDS results show that the metallic elements were also detected in the thermal residues, including $\mathrm{Fe}, \mathrm{Al}, \mathrm{Mg}, \mathrm{Na}$, and $\mathrm{Ca}$. In a word, the thermal decomposition of oily sludge can produce usable metals in both air and nitrogen atmosphere. Finally, the microstructures of solid products were observed using SEM and compared in Fig. 11. SEM results revealed that the residue had a porous structure and that the solid particles were more loosely arranged for samples heated under nitrogen atmosphere compared with those heated under air atmosphere. These characterized microscopic components and structures can guide the reuse of solid products of oily sludge. For example, $\mathrm{Fe}$ and $\mathrm{Al}$ can be used as active constituents of flue gas desulfurizer [26, 27]. Similarly, $\mathrm{Mg}, \mathrm{Ca}$, and $\mathrm{Na}$ can be used to improve the alkalinity of adsorbing materials.

\section{Conclusions}

This experimental comparative study demonstrated the effects of atmosphere on the thermal decomposition processes and products of oily sludge. First, oily sludge thermally degraded more thoroughly under air atmosphere than nitrogen atmosphere. The final thermal residue was $26.6 \%$ under air atmosphere and 35.8\% under nitrogen atmosphere. Oily sludge thermally degraded exothermically under nitrogen atmosphere, and the maximum exothermic peak occurred between 454.0 and $586.0^{\circ} \mathrm{C}$. Oily sludge produced fuel gases under nitrogen atmosphere but only combustion gases under air atmosphere. Comparing the microresults between the air and nitrogen atmospheres, the effects of atmosphere are smaller on the thermal residues than on the gaseous products. The thermal residues of oily sludge can be reused as a critical component of desulfurization materials. These results provide basic and essential data regarding effective treatment of and resource recovery from oily sludge.

\section{Acknowledgments}

This work was supported by the National Key R\&D Program of China under grant 2019YFC0810703 and 2019YFC0810701.

\section{Conflict of Interest}

The authors declare no conflict of interest.

\section{Referencess}

1. SHARMA S., AGRAWAL V., AKONDI R.N. Role of biogeochemistry in efficient shale oil and gas production. Fuel, 259 (11), 116207, 2020.

2. LIU Y., ZHOU H., LIU L. Firefighting emergency capability evaluation on crude oil tank farm. Procedia Engineering, 211, 506, 2018.

3. SHOBA B., JEYANTHI J., VAIRAM S. Synthesis, characterization of cellulose acetate membrane and application for the treatment of oily wastewater. Environmental Technology, 41 (12), 1590, 2020.

4. WANG Z.H., ZHANG L., LI J.X., ZHONG H. Disposal of oily sludge. Petroleum Science and Technology, 33 (9), 1045, 2015.

5. GAO N.B., LI J.Q., QUAN C., TAN H.Z. Product property and environmental risk assessment of heavy metals during pyrolysis of oily sludge with fly ash additives. Fuel, 266 (1), 117090, 2020.

6. LIU X.N., YAO T.T., LAI R.Q., XIU J.L., HUANG L.X., SUN S.S., LUO Y.J., SONG Z.Z., ZHANG Z.Z. Recovery of crude oil from oily sludge in an oilfield by sophorolipid. Petroleum Science and Technology, 37 (13), 1582, 2019.

7. DU M.M., LI J.L., WANG F.F., et al. The sludge based adsorbent from oily sludge and sawdust: preparation and optimization. Environmental Technology, 2020.

8. LIN B.C., WANG J., HUANG Q.X., ALI M., CHI Y. Aromatic recovery from distillate oil of oily sludge through catalytic pyrolysis over $\mathrm{Zn}$ modified HZSM-5 zeolites. Journal of Analytical and Applied Pyrolysis, 128, 291, 2017.

9. LI P., ZHANG X., WANG J., GUO H.W., CHEN Y.X., WANG Z.B., YAN B.J., CHEN D. Process characteristics of catalytic thermochemical conversion of oily sludge with addition of steel slag towards energy and iron recovery. Journal of Environmental Chemical Engineering, 8 (4), 103911, 2020.

10. HU G.J., LI J.B., ZENG G.M. Recent development in the treatment of oily sludge from petroleum industry: a review. Journal of Hazardous Materials, 261, 470, 2013.

11. WANG J., HAN X., HUANG Q.X., MA Z.Y., CHI Y., YAN J.H. Characterization and migration of oil and solids in oily sludge during centrifugation. Environmental Technology, 39 (10), 1350, 2018.

12. AI-DOURY M.M.I. Treatment of oily sludge using solvent extraction. Petroleum Science and Technology, 37 (1), 190, 2019.

13. LI G., GUO S.H., YE H.F. Thermal treatment of heavy oily sludge: resource recovery and potential utilization of residual asphalt-like emulsion as a stabilization/ solidification material. RSC Advances, 5 (127), 105299, 2015.

14. PARHAMFAR M., ABTAHI H., GODINI K., SAEEDI K., KOOLIVAND A. Biodegradation of heavy oily sludge by a two-step inoculation composting process using synergistic effect of indigenous isolated bacteria. Process Biochemistry, 91, 223, 2020.

15. WANG Z.Q., GUO Q.J., LIU X.M., et al. Low temperature pyrolysis characteristics of oil sludge under various heating conditions. Energy Fuels, 21 (2), 957, 2007. 
16. LIU C., LIU J.Y., SUN G., XIE W.M., KUO J.H., LI S.P., LIANG J.L., CHANG K.L., SUN S.Y., BUYUKADA M., EVRENDILEK F. Thermogravimetric analysis of (co-) combustion of oily sludge and litchi peels: combustion characterization, interactions and kinetics. Thermochimica Acta, 667, 207, 2018.

17. LIN B.C., HUANG Q.X., CHI Y. Co-pyrolysis of oily sludge and rice husk for improving pyrolysis oil quality. Fuel Processing Technology, 177, 275, 2018.

18. CHEN G.Y., LI J.T., LI K., LIN F.W., TIAN W.Y., CHE L., YAN B.B., MA W.C., SONG Y.J. Nitrogen, sulfur, chlorine containing pollutants releasing characteristics during pyrolysis and combustion of oil sludge. Fuel, 273 (1), 117772, 2020.

19. PETROVSKY E.A., KOLENCHUKOV O.A., SOLOVYEV E.A. Study of pyrolysis of oil sludge. IOP Conference Series Materials Science and Engineering, 537, 032082, 2019.

20. TANG X., WEI X., CHEN S. Continuous pyrolysis technology for oily sludge treatment in the chain-slap conveyors. Sustainability, 11 (13), 67, 2019.

21. MOKHTAR N.M., ETHAIB S., OMAR R. Effects of microwave absorbers on the products of microwave pyrolysis of oily sludge. Journal of Engineering Science and Technology, 13 (10), 3313, 2018.
22. ZHAO S., ZHOU X.H., WANG C.Y., JIA H.Z. Dewatering and low-temperature pyrolysis of oily sludge in the presence of various agricultural biomasses. Environmental Technology, 39, 2715, 2018.

23. JÔNATAS V.M., RODRIGO J.F., MÔNICA R. Copyrolysis of oil sludge with polyolefins: Evaluation of different $Y$ zeolites to obtain paraffinic products. Journal of Environmental Chemical Engineering, 8 (3), 103805, 2020.

24. YUAN J.J., TU J.L., XU Y.J., QIN F.G.F., LI B. Thermal stability and products chemical analysis of olive leaf extract after enzymolysis based on TG-FTIR and Py-GCMS. Journal of Thermal Analysis and Calorimetry, 132, 1729, 2018

25. CHENG S., WANG Y.H., FUMITAKE T., KOUJI T., LI A., KUNIO Y. Effects of steam and oil sludge ash additive on the products of oily sludge pyrolysis. Applied Energy, 185 (1), 146, 2017.

26. LIU J.G., JIANG X.M., ZHOU L.S., HAN X.X., CUI Z.G. Pyrolysis treatment of oil sludge and model-free kinetics analysis. Journal of Hazardous Materials, 161 (2), 1208, 2009. 
